\title{
Cesário Verde, nem lá nem cá
}

Júlia Vasconcelos Studart*

\section{Resumo:}

Este artigo trata da relação da poesia de Cesário Verde com alguns vetores da tradição da poesia portuguesa até os finais do século XIX. A idéia é mostrar o quanto a sua poesia invade esta tradição a partir de um móbil de não pertencimento - o seu nem lá nem cá - e de como ele arma sua poesia neste espaço da tradição que é o seu exato sem lugar no espaço ao propor uma modulação do mito babélico da Lisboa moderna.

\section{Palavras-chave:}

Poesia portuguesa, modernidade, cidade, Babel, espaço

Cesário Verde, comerciante da loja de ferragens na baixa Lisboa e exportador de cebolas, tomates, laranjas e uvas, é o poeta "que não pertenceu", diz dele Carlos Felipe Moisés (2001, p. 208). Não pertencer tem a ver, de alguma maneira, com uma idéia frágil de geração e cronologia a que Cesário Verde comparece, primeiro, cumprindo uma espécie de recusa e, segundo, tomando distância dos ideais que atravessavam as questões poéticas de Portugal em finais do século XIX, como as de Antero de Quental, por exemplo, que reclama uma poesia que "tenha uma comunicação direta e constante com o seu tempo" e que volte a caminhar "armada no meio das lutas dos homens" (QUENTAL, 1874, reprodução sem página). Cesário Verde é o poeta que elabora sua poética como um empenho de aproximação do espaço onde o seu corpo está, onde seu corpo vive como uma freqüência, um hábito, uma morada. Este espaço é o que ele ocupa entre as questões que envolvem a Lisboa moderna e o campo, na quinta que tem em Linda-a-Pastora, como uma espécie de lugar-limite para sua poesia; um espaço que é a pequena demora do homem moderno na atmosfera da rua como rua do mundo.

\footnotetext{
*Doutoranda, Universidade Federal de Santa Catarina (UFSC/CNPq).
} 
Carlos Felipe Moisés diz que Cesário adota os temas desse espaço porque tem que andar por ele, é o poeta pintor, retratista do cotidiano, é "o poeta das coisas ao redor: formas, cores e cheiros do ambiente urbano e rural; pessoas e objetos palpáveis; ideias, sentimentos e aspirações enraizados nas reais circunstâncias de vida" (MOISÉS, 2001, p. 209). É óbvio que a atmosfera de Cesário Verde está vinculada a algo da atmosfera de Charles Baudelaire e suas correspondências - "Les parfums, les couleurs et les sons se répondent" (BAUDELAIRE, 1985, p. 114) - e de toda a relação que este tinha com seus temas como poeta ao apontar para esta rua do mundo e do que disse dele, por exemplo, Walter Benjamin: que é o poeta que "(...) vê refletida em tudo a própria melancolia" (BENJAMIN, 1991, p. 84); que é o poeta que tem interesse pela multidão, pela massa em sua flanêrie: "a massa lhe é algo tão pouco exterior que nos permite seguir de perto, em sua obra, pelo modo como ele resiste ao seu envolvimento e à sua atração" (Idem, p. 84); e que é o poeta que entende que "As correspondances são os dados do 'rememorar'. Não são dados históricos, mas da pré-história. Aquilo que dá grandeza e importância aos dias de festa é o encontro com uma vida anterior" (Idem, p. 133).

Esta relação com a poesia de Baudelaire, de alguma maneira, desdobra a poesia de Cesário Verde para esta vida anterior, o que por sua vez leva a este não pertencimento. Isto talvez tenha a ver também com o fato de Cesário Verde ter publicado apenas oito ou nove poemas em vida, em alguns periódicos e outras publicações de ocasião que mesmo the torcendo o nariz imprimiam lá algo destes poemas. Depois, Cesário Verde não conseguiu organizar estes poucos poemas em um volume que pudesse virar livro; e, mais ainda, com o fato de Silva Pinto, logo depois de sua morte, aos 31 anos, tomar posse destes pouquíssimos e quase raros poemas ajustando-os à medida de sua precisão justificada como se tivesse sido um legado que supostamente Cesário Verde o incumbira de cumprir: fazer-Ihe poeta. Daí, o livro único, O Livro de Cesário Verde, publicado pela primeira vez em abril de 1887, com apenas 200 exemplares e destinado a ofertas, concentra toda esta sua pequena produção numa divisão arbitrária feita por Silva Pinto, em três partes: Crise Romanesca, Naturais e Poesias Dispersas. Bernardo Soares, um dos heterônimos de Pessoa, no fragmento de número 106 de seu Livro do Desassossego, diz desta circunstância de Cesário Verde como aquele que ao lançar na experiência da rua a sua poesia lança também esta mesma poesia em uma espécie de não existência: "O que ele foi sempre, coitado, foi o Sr. Verde empregado no comércio. O poeta nasceu depois de ele morrer, porque foi depois de ele morrer 
que nasceu a apreciação do poeta" (PESSOA, 1999, p. 133). E é o mesmo Fernando Pessoa, através de Alberto Caeiro, o heterônimo-mestre, que escreve e relê este poeta que nasce depois de morto no terceiro fragmento de seu "O Guardador de Rebanhos":

Ao entardecer, debruçado pela janela, E sabendo de soslaio que há campos em frente, Leio até me arderem os olhos O Livro de Cesário Verde.

Que pena que tenho dele! Ele era um camponês Que andava preso em liberdade pela cidade.

Mas o modo como olhava para as casas, E o modo como reparava nas ruas, E a maneira como dava pelas pessoas, É o de quem olha para árvores, E de quem desce os olhos pela estrada por onde vai andando E anda a reparar nas flores que há pelos campos...

Por isso ele tinha aquela grande tristeza

Que ele nunca disse bem que tinha,

Mas andava na cidade como quem anda no campo

E triste como esmagar flores em livros

E pôr plantas em jarros...

(CAEIRO, 2001, p. 28)

O que se percebe é que as leituras de Bernardo Soares e Alberto Caeiro parecem confirmar o não pertencimento de Cesário Verde ao fin de siècle português, que mesmo não acatando de pronto a poesia de um Antero de Quental (Odes Modernas, de 1865), de um Gomes Leal (As Claridades do Sul, de 1885 ) ou de um Guerra Junqueiro ( $A$ velhice do padre eterno, de 1885 ) não demora a lê-los e colocá-los como poetas da nacionalidade, principalmente este último. Caeiro, por exemplo, confirma isso ao dizer da pena que tem dele, do quanto ele the parece um camponês deslocado pela cidade, desta cidade a ferir o camponês, de como ele olha para as pessoas como quem olha para árvores, de uma grande tristeza que o afunda (uma melancolia herdada como spleen que paira sobre a poesia da segunda metade do século XIX que dialoga com a poesia de Baudelaire), de suas andanças na cidade como quem anda no campo 
etc. O próprio Cesário Verde em uma carta para seu amigo Antônio de Macedo Papança, o Conde de Monsaraz, datada de 29 de agosto de 1880, diz:

Ah! Quanto eu ia indisposto contra tudo e contra todos! Uma poesia minha, recente, publicada numa folha bem impressa limpa, comemorativa de Camões, não obteve um olhar, um sorriso, um desdém, uma observação! Ninguém escreveu, ninguém falou, nem num noticiário, nem numa conversa comigo; ninguém disse bem, ninguém disse mal! Apenas um crítico espanhol chamava às chatezas dos seus patrícios e dos meus colegas - pérolas - e afirmava - fanfarrão! - que os meus versos "hacen malísima figura en aquellas páginas impregnadas de noble espíritu nacional".

Tu mesmo, meu caro, enviando-me o teu poema tão fino e tão mimoso, e que, embora não seja verdadeiro e justo psicologicamente e historicamente, é todavia, como poesia, um sublime desenho linear de sentimento, tu mesmo, na dedicatória pões expansões afetuosas, generosidades de estima; mas literariamente parece que Cesário Verde não existe. (VERDE, 2006, p. 189-190)

Esta carta tem a ver com a publicação de seu poema que mais o aproxima de Baudelaire e da releitura que Fernando Pessoa faz dele para inseri-lo de alguma maneira no modernismo português, "O Sentimento dum Ocidental". Nesse mesmo período Cesário Verde escreve um pequeno bilhete sem assinatura ao editor do Jornal, Emídio de Oliveira - por causa da tal edição especial em homenagem a mais um centenário de morte de Camões, Portugal de Camões, e da publicação do poema em questão -, e diz que "Não poderia eu, por falta de aptidão, dedicar um trabalho artístico especial a Luís de Camões; mas julgo que fiz notar menos mal o estado presente desta grande Lisboa, que em relação ao seu glorioso passado, parece um cadáver de cidade" (VERDE, 2006, p. 246). Cito abaixo alguns trechos do longo poema:

\section{Ave Maria}

Nas nossas ruas, ao anoitecer,

Há tal soturnidade, há tal melancolia,

Que as sombras, o bulício, o Tejo, a maresia,

Despertam-me um desejo absurdo de sofrer.

O céu parece baixo e de neblina,

O gás estravassado enjoa-me, perturba;

E os edifícios, com as chaminés, e a turba

Toldam-se duma cor monótona e londrina.

(...) 


\section{Noite Fechada}

(...)

Na parte que abateu o terremoto,

Muram-me as construções retas, iguais, crescidas;

Afrontam-me, no resto, as íngremes subidas,

E os sinos dum tanger monástico e devoto.

(...)

E eu sonho o Cólera, imagino a Febre, Nesta acumulação de corpos enfezados;

Sombrios e espectrais recolhem os soldados;

Inflama-se um palácio em face de um casebre.

(...)

Triste cidade! Eu temo que me avives

Uma paixão defunta! Aos lampiões distantes,

Enlutam-me, alvejando, as tuas elegantes,

Curvadas a sorrir às montras dos ourives.

4. Horas Mortas

(...)

E enorme, nesta massa irregular

De prédios sepulcrais, com dimensões de montes,

A Dor Humana busca os amplos horizontes,

E tem marés, de fel, como um sinistro mar!

(VERDE, 1995, p. 97-105)

Este poema é talvez o seu emblema e sua assinatura como poeta, a sua dor humana, a marca pendular entre a sua não-existência e Lisboa, a cidadecadáver. O poeta como aquele que se lança à rua para cumprir uma responsabilidade com a poesia: o que é material antipoético, a cidade, o que é o espaço onde a poesia parece não haver, onde a poesia não há, é também o único princípio para uma poesia que se quer como uma prospecção do presente, um saturar-se de agoras como um sentido de acesso, um sentido por fazer. Como diz Jean-Luc Nancy: "O sentido de poesia é um sentido sempre por fazer" (NANCY, 2005, p. 10). A Lisboa de Cesário Verde é um presente porque tem presença, diz Eduardo Lourenço, Lisboa tem uma presença para um outro Portugal, presença "da qual cada um escolhe a face simbólica idealizante ou denunciadora: procissões de um colorido miserabilista sem igual, moleirinhas e pegureiros ideais, lojistas distraídos, varinas apopléticas, mães-coragens de um povo sem ela, burguesinhas oferecendo-se de graça à fenda do sonho (...)" 
(LOURENÇO, 1978, p. 99). Assim, ele se lança à rua para ter na rua uma experiência de poesia que não há na tradição portuguesa até então, para dizer do quanto "a realidade comparece na sua dupla face arcaizante e contemporânea" (Idem, p. 99) - em um poema como "Num Bairro Moderno", por exemplo, quando fala de uma "larga rua macadamizada"; cito um trecho:

Dez horas da manhã; os transparentes

Matizam uma casa apalaçada;

Pelos jardins estancam-se os nascentes,

E fere a vista, com brancuras quentes,

A larga rua macadamizada.

(...)

Bóiam aromas, fumos de cozinha;

Com o cabaz às costas, e vergando,

Sobem padeiros, claros de farinha;

$E$ às portas, uma ou outra campainha

Toca, frenética, de vez em quando.

E eu recompunha, por anatomia,

Um novo corpo orgânico, aos bocados.

Achava os tons e as formas. Descobria

Uma cabeça numa melancia,

E nuns repolhos seios injectados.

(...)

(VERDE, 1995, p. 64)

A rua de Cesário Verde não é mais apenas uma cartografia da cidade moderna, mas uma coleção íntima de suas circunstâncias citadinas, com brita, breu e areia, e o que nela pode constar de assombro e desamparo. A rua é uma figuração do rosto do poeta que precisa lançar-se ao chão, sem mito e sem história, para criar uma variante de expressão que faz da rua o seu mundo e do mundo um lugar desamparado para fazer a poesia, fazer a poesia como um novo corpo orgânico. A rua é a sua Babel, seu desvario.

A professora e crítica portuguesa Maria Ema Tarracha Ferreira, no prefácio da edição d'O livro de Cesário Verde que uso para este trabalho (ver bibliografia), diz que é por causa de uma inadaptação crescente a um ambiente que praticamente o ignorava como poeta e a necessidade de fugir à monotonia cotidiana, o que talvez justifique o seu desejo de evadir-se tantas vezes, desejo que está expresso nas suas solitárias deambulações pelas ruas de Lisboa, 
sempre num caminhar cadenciado, vagaroso, quase tênue, uma linha de postura que está inscrita em seus poemas como um mal-estar:

(...) nas caminhadas pelos arrabaldes, actividade física em que se compraz e que, segundo confessa, o prostra. Mas o mal-estar é mais fundo e o poeta desabafa: "Não me sinto bem em parte nenhuma e ando cheio de ansiedades de coisas que não posso nem sei realizar". (TARRACHA apud VERDE, 1995, p. 17)

E mais adiante, ao final do texto, quando ela comenta acerca de um caráter de transfiguração dos sentidos que Cesário dispõe em seus versos, entre a sua percepção do mundo e o que o mundo lhe aponta, ela diz que há um "autêntico Cesário", que seria aquele que todos recordamos, o que "não fantasia, evoca raramente e, quando imagina, recria a realidade, transfigurando-a para a tornar mais real; (...) a transfiguração da realidade não é um pretexto para fugir ao concreto, mas o único processo de captar a essência da própria representação do real" (Idem, p. 28). O vestígio que é possível articular a partir do comentário de Maria Tarracha é que Cesário Verde parece armar em sua poesia um lugar neste espaço que é o seu exato sem lugar no espaço, quando se coloca numa modulação do mito babélico, talvez, uma babel desenfreada, um nem lá nem cá do mito. Tanto que numa outra carta a Macedo Papança, sem data precisa, sabe-se apenas que do ano de 1886, escreve numa anotação breve mais ou menos na metade da carta um sopro de imprecisão quando compara o seu papel ao "papel almaço" de outros poetas seus contemporâneos; este sopro impreciso aponta para seu não pertencimento, seu nem lá nem cá, sua queda no chão, a queda de sua poesia no chão da história da literatura portuguesa até então, e esta queda não é senão a sua disposição para sair, para se mover, de alguma forma:

Devo ser alegre?

Devo ser triste?

Que de qq aí acima.

(VERDE, 2006, p. 192)

Mas é em seu poema "A Débil", que Cesário Verde apresenta e confere a Lisboa, cidade-cadáver, uma idéia de espaço que ele cumpre como se fosse a sua Babel. Lisboa é a cidade do mito desfeito, do espaço desamparado, a cidade desamparada, a figuração da Babel moderna, agora ao mesmo tempo velha e 
corruptora, uma outra cidade anônima da passante quase baudelariana; cito as duas estrofes iniciais do longo poema de Cesário, abaixo:

Eu, que sou feio, sólido, leal,

A ti, que és bela, frágil, assustada,

Quero estimar-te, sempre, recatada

Numa existência honesta, de cristal.

Sentado à mesa dum café devasso,

Ao avistar-te, há pouco, fraca e loura,

Nesta Babel tão velha e corruptora,

Tive tenções de oferecer-te o braço.

(VERDE, 1995, p. 61)

E mesmo que ele confronte toda uma perspectiva da poesia portuguesa de então e mesmo diante do impasse cruzado do sem lugar da cidade, ainda usa a noção do mito da babel como um totem, porque a respeita como tal ao inscrevê-la com letra maiúscula. Cesário Verde não é o poeta que pode interromper e desfazer o mito, mas apenas o dono de uma loja de ferragens no subúrbio de Lisboa. O poema seria, para ele, ainda, o lugar onde o mito se cumpre, mesmo que o poema cumpra também o lugar do ordinário citadino, daí uma suspeita para o seu não pertencimento, o seu nem lá nem cá. Assim, talvez, faça sentido ler a impressão de Bernardo Soares, o desamparado, ao dizer que o poeta só veio depois da morte, e veio também como mito, mas ao mesmo tempo é o poeta que de alguma maneira tentou tocar o "fundo escuro" da desordem das coisas do mundo ao redor, aquilo que Jean-Luc Nancy elabora como um suplemento para a poesia: que a própria poesia pode perfeitamente encontrar-se onde não existe propriamente poesia, que "Ela mesmo pode ser o contrário ou a rejeição da poesia, e de toda a poesia. A poesia não coincide consigo mesma: talvez seja essa não-coincidência, essa impropriedade substancial, aquilo que faz propriamente a poesia" (NANCY, 2005, p. 10-11). Para Nancy "o poema é um sentido abolido como intenção e como finição: voltando-se não sobre a sua vontade mas sobre o seu fraseado. Não fazendo já problema, mas acesso" (NANCY, 2005, p.18).

$E$ é como acesso que se pode pensar uma babel ou algo babélico como aquilo que pode se avizinhar da metáfora da costureira, sugerida por Barthes: são peças e pedaços cruzados, "peças, pedaços são submetidos a cruzamentos, a arranjos, a ajustes" (BARTHES, 2004, p. 353). Uma peça única feita de muitas 
outras peças menores, desiguais, como uma espécie de arte original, que é também o que se aproxima da caixa de costura de Walter Benjamin, quando ele relembra uma passagem de sua infância em que sua mãe descobre que era preciso ajustar a sua roupa de marinheiro. Benjamin diz que entre carretéis de todas as cores, cartelas pretas onde ficavam as agulhas e tesouras confinadas em suas capas de couro, havia uma espécie de "fundo escuro" que era a representação da mais pura desordem, um desvario de coisas em oposição ao "sortimento multicolor das sedas, das finas agulhas e das tesouras de diversos tamanhos" (BENJAMIN, 1987, p.128) e ao zelo exigido para com a roupa já vestida. Este "fundo escuro" das memórias de Benjamin é o lugar da deformação do espaço, daquilo que se contorce, de tudo aquilo que não serve mais e que começa a montar aleatoriamente, no seu abandono, uma grande babel que se faz com aquilo que não tem existência, que é também a dimensão de um cadáver: quinquilharias, sobras de tecidos, botões, tesouras cegas etc. Benjamin vai dizer que o fundo escuro é "onde reinava o entrelaçado desfeito, e onde sobras de elástico, ganchos, colchetes, retalhos de seda, se amontoavam. Nesse refugo também havia botões; muitos de tal feitio como jamais se viu em roupa alguma" (Idem, p.129). Assim, a partir da imagem da costureira de Barthes que ajusta as coisas, que dá lugar às coisas numa espécie de arte primeira, uma vida interior, também é possível construir uma outra idéia, a da deformação, que está no fundo sem fundo e infinito da caixa de costura de Benjamin, mas que pode habitar qualquer lugar abstruso da memória e da história, o "fundo escuro" da desordem das coisas, lugar de refugo para tudo aquilo que é posto de lado, como a poesia de Cesário Verde. No poema "Setentrional", do qual cito um trecho abaixo, ele diz:

Talvez já te esquecesses, ó bonina, Que viveste no campo só comigo, Que te osculei a boca purpurina, E que fui o teu sol e o teu abrigo.

Que fugiste comigo da Babel, Mulher como não há nem na Circássia, Que bebemos, nós dois, do mesmo fel, E regámos com prantos uma acácia.

(...)

(VERDE, 1995, p. 38) 
Numa carta ao seu amigo Bettencourt Rodrigues, numa temporada que passou em sua quinta em Linda-a-Pastora, datada de 16 de novembro de 1879, numa tentativa de fuga da Babel, quando Lisboa Ihe parece inacessível, Cesário escreve o quanto não consegue ver nada através de seu frágil "Ionga-vista", não consegue ver nem para cá nem para lá:

Meu amigo - Tem chovido bastante e há dias que temos as comunicações cortadas com Lisboa, como numa ilha por um mar bravo. (...)

A tua estada em Paris faz-me um imenso mal, a mim particularmente: produz-me a idéia fixa, a monomania de partir para aí. Faço esforços inauditos para presenciar o que se passa nesse mundo superior e descuido-me deploravelmente do que me rodeia. Como um astrônomo abstrato assestei para o estrangeiro um telescópio e cansado dos olhos, dorido dos rins, olho atentamente, constantemente. Podem dar-me uma facada, o que é provável, que não verei quem ma der.

Ora acontece que disponho apenas de um longa-vista ordinário da pobre agência de navios de vela, e que não vejo para cá nem para lá; e esta impossibilidade acabrunhame muitas vezes a vida, rala-me, faz-me velho antes do tempo. (VERDE, 2006, p. 197198)

Numa prospecção dessa questão, o poeta português Ruy Belo, numa releitura de Cesário Verde feita na década de 1970, diz que "a palavra é o mais perigoso dos bens" e que o "homem tem de a utilizar para testemunhar o que é. Ao lançar mão dela, expõe o seu ser, isto é, põe-na a descoberto e arrisca-o" (BELO, 2002, p. 90-91). Assim, de outra maneira, Ruy Belo parece traçar a linha de uma imagem tênue e arriscada do que pode ser a leitura de uma poesia num território desconhecido, mas também quase irreconhecível, um território inseguro, instável, para de novo mover a poesia e reler a tradição da literatura portuguesa a partir daquilo que não Ihe pertenceu, como, de certa maneira, a poesia de Cesário Verde. E ainda como prospecção, que serve como nota de releitura, quase exatamente um século depois ( $O$ Livro de Cesário Verde foi publicado em 1887), no Brasil, Paulo Leminski, em seu livro Distraídos Venceremos, publicado em 1987, outro final de século, termina um poema sem título que gira em torno de uma despedida das coisas ao redor - "Adeus, coisas que nunca tive / dívidas externas, vaidades terrenas, / lupas de detetive, adeus" (LEMINSKI: 1987, p. 88) - despedindo-se também do mito da torre de babel e impondo sobre este mito o impasse do desequilíbrio, o nem lá nem cá, como anacronismo, como destruição; o desequilíbrio como uma interrupção do mito, jogá-lo ao chão, dar-lhe um uso comum e precário ou um uso nenhum. Assim, 
diz de não pertencer como uma potência para a poesia por dentro das circunstâncias de desamparo para o poeta. O poeta, para Leminski, é apenas o que tudo nomeia mas que nada vale, o que provoca "a sopa rala que mal dá para dois", o "de sempre" e "de bosta" e o poema, talvez, um outro sentimento de ocidental, outro lance de dados. Diz Leminski no final do poema em questão:

Adeus, mundo cruel, fábula de papel,

sopro de vento, torre de babel,

adeus, coisas ao léu, adeus.

(LEMINSKI, 1987, p. 88)

A babel, para Leminski, não passa de uma coisa ao léu, um catatau de coisas ao léu (como arma em seu romance-idéia-invenção de 1975, o Catatau) sem mito algum a não ser sua própria distração vencida. Desdobramentos da questão.

\section{Referências bibliográficas:}

ANTONIO, Jorge Luiz. Cores, forma, luz, movimento - A poesia de Cesário Verde. São

Paulo: Fafesp, 2002.

BARTHES, Roland. O Rumor da Língua. Trad. Mário Laranjeira. 2a ed. São Paulo: Martins Fontes, 2004.

BAUDELAIRE, Charles. As Flores do Mal. Trad. Ivan Junqueira. Rio de Janeiro: Nova Fronteira, 1985.

BELO, Ruy. Na Senda da Poesia. Lisboa: Assírio e Alvim, 2002.

BENJAMIN, Walter. Rua de Mão Única. Trad. Rubens Rodrigues Filho e José Carlos Martins Barbosa. São Paulo: Brasiliense, 1987.

. Charles Baudelaire - Um Lírico no Auge do Capitalismo. Trad. José

Carlos Martins e Hemerson A. Baptista. 2a ed. São Paulo: Brasiliense, 1991.

BUENO, Aparecida de Fátima et al (Org). Literatura Portuguesa - História, Memória e Perspectivas. São Paulo: Alameda, 2007.

CAEIRO, Alberto. Poemas. São Paulo: Cia das Letras, 2001.

LEMINSKI, Paulo. Distraídos Venceremos. São Paulo: Brasiliense, 1987.

LOPES, Silvina Rodrigues. Anomalia Poética. Lisboa: Vendaval, 2005.

LOURENÇO, Eduardo. O Labirinto da Saudade. Lisboa: Dom Quixote, 1978.

MOISÉS, Carlos Felipe. O Desconcerto do Mundo. São Paulo: Escrituras, 2001. 
NANCY, Jean-Luc. A Resistência da Poesia. Trad. Bruno Duarte. Lisboa: Vendaval, 2006.

PESSOA, Fernando. O Livro do Desassossego - composto por Bernardo Soares, ajudante de Guarda-Livros na cidade de Lisboa. São Paulo: Cia das Letras, 1999.

QUENTAL, Antero de. Tendências da Poesia Contemporânea, em AZEVEDo, Guilherme. D'a Alma Nova. Lisboa, Typographia Sousa e Filho, 1874. (reprodução)

VERDE, Cesário. O Livro de Cesário Verde. Lisboa: Ulisséia, 1995. . Obra Poética integral - 1855-86 (tábua e cartas). Org. Ricardo Daunt. São Paulo: IPLB / Landy, 2006.

\title{
Title:
}

Cesário Verde, nor here, nor there

\begin{abstract}
:
The present essay deals with the relation of the poetry by Cesário Verde and some vectors of the traditions of the Portuguese poetry till the end of the nineteenth century. The intent is to show how much of his poetry invades such a tradition from a mobile of non pertaining to -his nor here, nor there- and of how he arms his poetry in such a space of the tradition, which is his exact without a place within the space as he proposes a modulation of the Babel myth of modern Lisbon.
\end{abstract}

\section{Keywords:}

Portuguese poetry, modernity, city, Babel, space 